\title{
Challenges Facing School Social Workers in Saudi Arabia
}

\author{
Abdulhadi Sharhan Alotaibi, Mohd Suhaimi Mohamad, Nor Jana Saim \& \\ Ezarina Zakaria
}

To Link this Article: http://dx.doi.org/10.6007/IJARBSS/v10-i12/8280

DOI:10.6007/IJARBSS/v10-i12/8280

Received: 01 November 2020, Revised: 26 November 2020, Accepted: 09 December 2020

Published Online: 19 December 2020

In-Text Citation: (Alotaibi et al., 2020)

To Cite this Article: Alotaibi, A. S., Mohamad, M. S., Saim, N. J., \& Zakaria, E. (2020). Challenges Facing School Social Workers in Saudi Arabia. International Journal of Academic Research in Business and Social Sciences, 10(12), 101-115.

Copyright: @ 2020 The Author(s)

Published by Human Resource Management Academic Research Society (www.hrmars.com)

This article is published under the Creative Commons Attribution (CC BY 4.0) license. Anyone may reproduce, distribute, translate and create derivative works of this article (for both commercial and non-commercial purposes), subject to full attribution to the original publication and authors. The full terms of this license may be seen

at: http://creativecommons.org/licences/by/4.0/legalcode

Vol. 10, No. 12, 2020, Pg. 101 - 115

http://hrmars.com/index.php/pages/detail/IJARBSS

JOURNAL HOMEPAGE

Full Terms \& Conditions of access and use can be found at http://hrmars.com/index.php/pages/detail/publication-ethics 


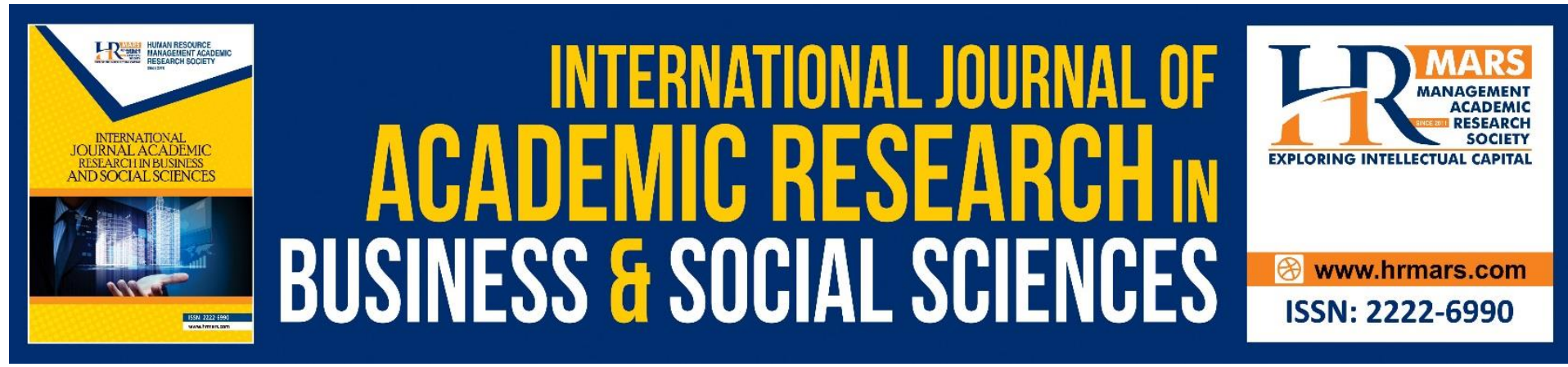

\title{
Challenges Facing School Social Workers in Saudi Arabia
}

\author{
Abdulhadi Sharhan Alotaibi ${ }^{1,2}$, Mohd Suhaimi Mohamad ${ }^{1}$, Nor \\ Jana Saim ${ }^{1}$ \& Ezarina Zakaria ${ }^{1}$ \\ ${ }^{1}$ Centre for Research in Psychology and Human Well-being, Faculty of Social Sciences and \\ Humanities, Universiti Kebangsaan Malaysia, Malaysia, ${ }^{2}$ Al Imam Mohammad Ibn Saud \\ Islamic University \\ Email: janasaim@ukm.edu.my
}

\begin{abstract}
In the Kingdom of Saudi Arabia (KSA), school social workers (SSW) faced challenges that hinder the performance of their required roles: such as administrative restrictions, inadequate level of professional training, unclear roles as well as society norms. Although, the existing literatures focused on the possible benefits associated with SSW, however it ignored their challenges which may influence the performance and the quality of the provided services. Therefore, the study aims to fulfill the existing gap by exploring the challenges of SSW in the KSA. The semi-structed interviews used to collect the data of 16 school social workers across Riyadh. Based on the thematic analysis, the study found major challenges: Administrative constraints, workload and occupational stress, and sociodemographic differences. The study recommends national organizations to overcome these challenges in order to enhance the performance and the quality of the services of SSW at schools in KSA.

Keywords: School Social Work, Social Work, Challenges, Saudi Arabia.
\end{abstract}

\section{Introduction}

Owing to globalization and internationalization, social work becomes an integral part of higher education systems worldwide (Amin, et al., 2019). Institutes and colleges concerned with social works have adopted the social and theoretical training of social workers in a manner that qualifies them to acquire experience, knowledge, and skills in order to be able to practice their professional roles in the field of social work, including schools. Social work in schools considered as one of the professions that emerged in response of rising concerns social problems among students. In order to overcome social problems among students, the school social workers interventions involved individuals, families, communities and policies (Nurzaimah et al., 2013). The social worker, while performing his professional obligations, gives assistance to students to benefit from the educational processes and helps the school to achieve its roles and functions.

The concept of social work at school is the provision of specific services to help students, individually or within groups to adapt to social and psychological problems and difficulties. According to studies (Alavi et al., 2012; Sopian et al., 2016), a school social worker could be 
among the primary intervention dealing with child abused cases among students. In the United Kingdom, a social worker trainee is both trained and qualified, to ensure that students are safe and well-cared for. Therefore, it has been highly recommended that qualified personnel are recruited for the job or trained according to job requirements before exposing them to childcare. In addition, a social worker can influence students' contribution to an effective effort in life and society. The social worker helps students to satisfy their needs and to make desired changes in their behavior. The social worker also helps them adapt themselves to their social environment, in their attempts to connect themselves with resources available within the community to achieve maximum social security.

In the KSA, the Ministry of Education has continuously employed social workers for a long time, despite a lack of monitoring, follow-up and weak identification of tasks, responsibilities, and roles. This has led to poor professional performance and expected outputs. However, the placement of school social workers in the organizational structure of the school is commendable and appeared to be in the right direction. A social worker is considered as educational, vocational and technical support to connect school, student, family and community at large (Albrithen \& Briskman, 2014).

The establishment of social work at schools in the KSA was in 1954 and can be summarized in five stages. The preparatory stage, necessitated by the increase in the number of students and schools, and the absence of educational role, is supposed to be highlighted by the teacher. Besides the educational roles (for teachers), this has affected the roles of students and their relationships with each other, which has led to the introduction of other new activities. The second stage is the foundation stage by which the Department of Education and Social Activity are established. The foundation stage is characterized by the presence of many social activities, including voluntary activities carried out by teachers in schools. These activities have created a kind of educational process between the students and their teachers (Al-Nasr, 2017; Soliman, 2013).

The third stage is the professional stage which uses the services of two social workers from the Arab Republic of Egypt. The third stage is located in the King Saud Scientific City in Jeddah, while the other, in Makkah. The roles of social workers are to supervise the processes of social activities by highlighting the roles of a social worker. The fourth stage in the establishment of social work in schools in the KSA is an important turning point when social works in schools are assigned to Saudi social workers. The first batch of Saudi social workers was 79, and five years later, the number rose to 416, 189 all assigned to girls' school (their terms of reference were different in different areas, especially in the main cities. The largest number recruited was in the city of Riyadh.

The fifth phase of the establishment of social work at schools in the KAS was the establishment of what was known as the General Directorate of Counseling and Guidance for students. The administration worked several years on changes that can be summarized in the abolition of the name of the school social worker and the development of another name "counseling and guidance". The change led to the opening of the doors to fill jobs as student counselors from teachers and holders of different disciplines, who may not be from the social sphere. There was a requirement of two semesters for the diploma in counseling. The program included a diploma in guidance and counseling for 27 credits hours. The program prepared graduates of the departments of psychology, sociology and social work to be 
qualified to work in the field of students counseling and guidance, to raise the level of performance and rehabilitation of students' counseling and guides in the field of education. Through the development of their expertise and skills, the program provided them with what help to perform scientifically and practically with the role they played in the educational process (Abu Al-Nasr, 2017).

Currently, there has been an increase in interest in social work as a career in the KSA. More so, a number of institutions of higher learning have departments of social works and they play a vital role in training social workers with the necessary skills. Starting with two institutions and a university is King Saud University. Presently, the number has increased to seven universities with social work departments, with some having master and doctoral programs. Six of these universities are for boys and girls and one Princess Noura bint Abdulrahman University, being reserved for girls only.

In the KSA, there are numerous tasks in which a social worker is assigned. This usually comes directly from supervisors such as the Ministry of Education, some of whom have been approved by the General Directorate of Counseling and Guidance and also from the Department of Education in the region as well as the school administration and some teachers. Social workers at school may perform a lot of routine work, such as filling in the required records, writing reports which may require a lot of time to complete. Professionals may face conflicts between their roles as professionals and their duties as employees. As employees, they must carry out the duties of their supervisors and senior managers. However, as a professional, tended to follow his own professional sense and did things that may conflict with regulations and instructions issued by the supervisors and the school administration or senior officials.

It is difficult for them to disobey and has to perform the administrative work. For example, occasionally, a social worker may be assigned as a substitute teacher for, physical education class, fine arts or other classes. A social worker is also controlled by administrators who assigned to work far from his job scope as a counselor or social worker. They did not have their own administration to advocate for them (Albrithen \& Briskman, 2014).

\section{Problem Statement}

Social workers, as professionals, may feel that they are not allowed to work due to many problems surrounding them such as administrative restrictions, inadequate level of training, inadequate professional form, and unclear roles. Working in such difficult situations, it is possible that the situation is not stable and the environment is not appropriate and encouraging for creativity. Social workers are most likely to separate their feelings and personal ideas from following the rules provided, professionally and practically. Social workers may be exposed to numerous critics about their professional performance and lack of interest in students' needs. The critics arise from unclear roles of the social workers. In addition, school administration often misunderstands the nature of the professional roles of social workers in bringing about changes and contributing to solving problems. Moreover, critics may lead to a vibration of trust and lack of understanding among school members (school principal, administrative staff, teachers, etc.) and the social workers. This may affect the direct practice of the social worker's role in schools (Sloan et al., 2017). 
Al-Goaib (1988) points out the challenges often faced by social workers when exercising their roles within the school, some of these challenges are in relation to customs, traditions, family cohesion and privacy. In the KSA society, there is a very high degree of sensitivity when they talk about their situation and their family problems to strangers. They believe that family issues should be discussed only within the family and relatives. As a result, social workers find difficulties in building professional relationships with students and their families to overcome their problems. Moreover, there is no governing body or department in the Ministry of Education that serves as a substitute for social workers who defended their rights and looked at the challenges they faced in the field.

In most institutions especially in schools, this has relegated the activities of social workers. The roles they perform in schools are unclearly defined and this has rendered their activities less important in the eyes of the schools and the community. The lack of a defined role for them to follow and what they actually do has have created a vacuum and this has affected their obligations. Therefore, there is a need to explore the roles of social workers in schools as well as the conflict of their roles compared to what they do in reality (Ahmadi, 2003; Balobaid et al., 2016). Therefore, this study is an attempt

- to explore the challenges of social workers at school in the KSA.

- to explore the experiences of social workers at school in the KSA

\section{Literature Review}

The National Association of Social Workers (2017) indicated that school social work is a unique and specialized field within the scope of the profession of social work. While social work refers to the provision of adjustments to the society, which relates to emotional and social lives of people, school social work narrows down the services to students with more specialty (Calis \& Calis, 2015). In this respect, school social workers refer to the professionally trained individuals, who provide services such as mental health training and counseling services at schools. A study by Nazihah et al. (2019) noted that the final year students of social work program are equipped with ethical behavior and leadership skills. Calis and Calis (2015) indicated that school social workers perform several duties, which include working out emotional problems with students, preparing the history of a child's social development, bringing together the family of a learner to ensure that the student performs better academic wise. In addition, Kelly et al. (2010) noted that social workers assist students with strategies for developing positive behaviors if a student was previously involved in rogue behaviors.

The practice of formal social work in Saudi Arabia dates back to 1953. It began with the rehabilitation of delinquents when an institution for the care of delinquents was established in the mentioned year. Immediately, in 1954, social work was introduced in schools. Urban social work, family and children's programs and health care began in the 1960s. However, modern professional practice in social work began with the establishment of the Ministry of Labor and Social Affairs in 1960 (Almaizar \& Abdelhamed, 2018). The social welfare services expanded considerably after the establishment of the Ministry of Labor and Social Affairs. Education, health, youth welfare and other social services have become a government responsibility.

Formally, the year 1965 was marked as the real beginning of practice of social work in Saudi Arabian schools. This specifically took off when 44 social workers from Egypt were given 
contract by the Ministry in the various schools in the KSA. The responsibilities that were given to the social workers in schools were gradually altered and transcended beyond counseling students to encompass traditional counseling services for personal and academic problems, along with assisting students with their career plans (Saleh, 1987).

Social workers in schools are expected to form productive professional relationships with all staff members in the school based on mutual respect and trust. The social workers are given the responsibility to carry out research related in their work which will provide possible and more efficient ways of carrying out social work, alone or with other social workers in other schools or other social supervisors in the school district or community. Furthermore, social workers are expected to develop their knowledge and experience, especially when in the field as this enhances efficiency. Finally, the social workers are supposed to present annual reports of their achievement, together with recommendations for improving the services (General Administration for Guidance and Counseling, 1997).

With the increasing number of social workers in the KSA schools, their activities have also increased; but the activities of social work still suffer from insufficient number of personnel. Due to the fact that social work in schools still depends heavily on non-Saudi social workers on temporary contracts, it does not implement all its methods. It is common that students do not seek help to solve their problems. An empirical study showed that only 22 percent of Saudi students come forward to ask for assistance from social workers in school, taking to mean that their activities is yet to be fully effective (Al-ajaln, 2000). Most of the problems which social workers deal with have been referred to by teachers or parents or may have been identified by the social workers themselves.

As a result of the nature of student-teacher relationship culture in the KSA, students highly respect their teachers, hence affecting students coming for counseling. Sometimes the students refuse to accept help, although this rarely occurs, because in the KSA, students show respect to older people in general and to teachers in particular. If occurs, students may seek assistance from the social workers (Al-ajlan, 2000).

The study uses the system theory as propose by David Easton to explain the research. The theory was used because of its importance and useful in explaining different effects especially in system like education and government policies. System theory guide this study to understand the nature of the challenges faced by social workers in schools and the levels in which they suffer from difficulties that may limit their optimization of their roles. Therefore, it is important to differentiate all of these levels and deal with them separately. Systems theory clearly explains these levels, which in this study were called based on the problem of the study. School social workers were also able to share their experiences with these challenges, helping them to achieve best practices and find possible solutions. Knowing and understanding the challenges and the team between them is important and necessary to deal with them (Christensen et al., 2018; Paat, 2013).

This study focuses on exploring the challenges facing social workers in Saudi Arabia schools. Consequently, the challenges facing social workers in schools were divided into macro, mezzo and micro levels. The challenges that are related to policies and regulations at the level of the Ministry of Education or the government are at the macro level (Ben-natan, 2014). As for the 
challenges related to the school administration and the school environment, they are at the mezzo level.

Finally, the challenges facing social workers and related to students and their families are micro level. Working to meet these challenges needs to be understood separately at different levels and deal with each level separately. Differentiating between the macro, mezzo and micro levels helps to have a comprehensive view of the challenges and how to deal with them. For example, at the macro level, unanimous specialists need to work on a large scale at the state level to claim their rights and try to issue some systems that help them to raise the level of their competence in work and remove all obstacles that limit their productivity (Becker et al., 2012; Ben-natan, 2014; Rogers et al., 2013).

\section{Method}

\section{Sample Size}

A list of 100 social workers was handed to the first author by the Saudi Arabian ministry of education in order to contact the social workers for the interview. The first author selected 80 informants base on purposive random sampling and the criteria set by the researcher (Patton, 1990). The criteria includes willingness to participate, hold a bachelor degree in social work, working as a social worker in schools in Riyadh more than one-year experience. Out of the 80 informants identified and contacted via emails only four (4) responded back and showed their interest to participate in the study. Therefore, in order to expand the sample size, a snowballing technique was used, that is each of the first informant were asked to recommend other person who will be willing to share their experience (Creswell, 1998). This method was used throughout until saturation is reached. The total numbers of 16 social workers were interviewed and each of the informants are selected from different school to obtain their experiences and challenges faced; the number also represents all the Schools in the city of Riyadh. The reasons why the study was conducted in Riyadh was because it has the highest number of schools in Saudi Arabia with highest number social workers.

\section{Data Collection}

Data are collected through semi-structured interviews by one-to-one (face to face) between the informants and the researcher. The interviews were done twice or sometimes thrice with some of the informants depending on their request. Each interview normally last between one hour (60 minutes) to one hour thirty minutes (90 minutes) depends on the willingness of the informants to express their feelings. All the interviews conducted were recorded in audio recorder. Though, the interview process was guided by the semi structure interview and saturation was closely observed by the researcher during the interviews. All the interviews were conducted in Arabic language to give the informants the ability to express their opinion freely. The interviews were also translated by a professional translator to avoid sentiment and bias by the researcher.

\section{Data Analysis}

In the present study, the researcher used the deductive approach to transmit data that were addressed to the research questions. The data obtain from the informants were analyzed manually using thematic analysis to generate codes, themes and sub-themes. Therefore, the data were analyzed through six stages as suggested by Creswell (1998), the first stage was familiarization of the data; at this stage the researcher engaged into reading the field notes 
and listening the audio recorded during the interview, in order for the researcher to understand the meaning of the data collected. Secondly, after the data are understood, the researcher begins the process of transcribing the audio interview into writing form and comparing it with the field notes. This process involves listening the audio of the interview over and over. The third stage was tag and labelling which means a process of reading the transcribed interview and underlining the important or key information stated by the informants and each information was tag with a name for easier identification in the next stage. After the tag and labelling process the researcher went back to start the coding known as identification of codes and this represent the fourth stage. After a critical evaluation and several discussions by the researchers on the identified codes. Then the codes are sorted into groups and each of the groups are identified with themes and sub-themes. The final stage the themes and sub-themes are giving a meaning and definition to reflects the informant's views and the research objective. Thus, the interpretation of the data and reporting of the study were explorative and descriptive nature.

\section{Trustworthiness}

The present study was qualitative in nature which attempt to understand the challenges faced by school social workers and how they dealt with such problem. This type of study requires trustworthiness to show the level of transparency and reflections on how well the research process is conducted (Dahlgren et al., 2007). However, in order to validate the reliability and test the trustworthiness of sampling, data collection techniques and the findings of the data obtained, the results passes and undergo several stages, such as the supervisory committee and also each informant was consulted with the transcribed interviews to check if something is omitted from the verbal interview. Triangulation was also used by the researchers to ensure the accuracy of the findings.

\section{Ethical Consideration}

The ethical standards are fulfilled by the formal approval of the Saudi Arabian ministry of education and school administrations. Before the commencements of the interview, informants are informed about the purpose of the study, the important of their roles and rights in the research. Confidentiality, method of data collection as well as their voluntary participation and their ability to withdraw at any time was also explained to each of the informants by the first author. When the informants are clear and satisfied with the ethical procedures and agree to participate a consent form is given to each informant to sign.

\section{Findings and Discussion}

Based on the scope of the study, the informants were asked to share the challenges and difficulties faced by the social worker at school. The main themes identified from the data are: challenges with administration, challenges with policy and regulations, challenges with families. A competence was a sub-theme that thought to be necessary by informants. The themes and sub-themes generated from the data are shown in Table 1. 
Table 1: Overview of sub-themes and themes

\begin{tabular}{ll}
\hline Sub-themes & Themes \\
\hline Specialization and competence. & Administrative constraints \\
Recognition & \\
Lack of resources & \\
Workload and occupational stress & Workload and occupational stress \\
Cultural diversity of the society & Sociodemographic differences \\
Family education level & \\
\hline
\end{tabular}

\section{Administrative Constraints}

Administrative constraints are issues or problems related to administrative processes or management. The social workers feel like the management are not concerned with issues related to their problems as people who guide the future generations. Based on the concerned express by the informants, three sub-themes emerged as a challenges and difficulties in discharging their responsibilities: specialization and competence, lack of resources and recognition.

\section{Specialization and Competence}

Informants made it clear that the reputation and image of social workers suffer greatly because of the established principles of insufficient attention to specialization considerations when it comes to appointing social workers mainly in schools. As a result of this, it has become evident that some social workers do not have the necessary skills in dealing with cases because they are not specialized and therefore a poor image of the work of social workers has been formed. For instance, Informants 7 remarked that: "Social workers lack the principles, foundations, and aspects of social work". This is consistent with what Rosenkoetter et al. (2007) refers to as the importance of having qualified social workers to do the job in schools, regarding the assistance of families during this transition of their children in school. Rosenkoetter et al. (2007) further maintained that social workers should be aware of several concerns that arise for many families. Since, social workers may be called on to assist young children's adjustment to the new preschool setting, either by teaching them directly or by advising family members, teachers, or therapists about ways to promote children's psychosocial health (Rosenkoetter et al., 2007).

Moreover, Altshuler and Webb (2009) emphasized that, consistent certification standards and corresponding professional preparation would increase the likelihood that school social workers are well equipped for the complex task of working with children and families, some of whom experience overwhelming difficulties. Altshuler and Webb (2009) also suggest that the image of the school will be challenged and their ability to work effectively within educational settings for the benefit of youths also will be challenged, without such presence, legitimacy, and qualifications recognized at the state and, ultimately, federal levels.

\section{Recognition}

Recognition of social worker was another issue administration constraint by the informants. The findings pointed out that the school administration was ignorant of the role of the social workers, and consequently, this gave rise to a lot of problems. For instance, one of the informants had this to say: 
"They do not know the real role of the social worker" when probed to give an example, he continues, "I mean, the head of the school wants you to be a mentor at one time and then a health worker and then she wants you to work as an administrative or monitoring other employee, and a teacher replacing the absent teachers in the class room" - Informant 9

This findings are in line with Huxtable (1998) who stated that school social workers were sent back to the classroom to supplement an inadequate supply of teachers, leaving the school social work staff ill equipped for intervening to reduce the social barriers that prevent children from attending school.

More so, Cherniss et al. (1976) also found that this social questioning and criticism of professional authority and other aspects of professional status often become an intensely experienced personal problem. As one young school social worker in their study said: "I just don't know what I should be. Should I be a facilitator? A rescuer? An expert? Parents and teachers expect me to be a disciplinarian" Informant 2 . Another study that run consistent with the findings of this study is Peckover et al. (2013) that found respondents highlighting the lack of a professional identity, misperceptions that supervisors had about the role of school social workers, and increasing breadth of demands on school social workers. Their study's informants reported a general sense of role confusion in those they encounter professionally. Thus, the following statement, made by one informant, summarizes the general concern expressed by informants in their study over the future role of the school social worker:

"I would like to do more "Social Work" such as groups, individual work, connecting families to resources, partnering with community services, etc. Instead, it seems as though the future will include less and less of that and more work with teachers on academic interventions, and progress monitoring. I will not even carry the title of School Social Work as early as next year." -Informant 6

Altshuler and Webb (2009) asserted, school social workers often face challenges of having to legitimize their presence as a school professional. Altshuler and Webb (2009) asked why are school social workers more often vulnerable to being underappreciated and not understood by school personnel than other mental health-based school professionals.

\section{Lack of Resources}

Lack of resources was another challenge identified by the informants and found it to be imperative. According to them, there is a scarcity of resources available to them (school social workers) to carry out their work properly. An example of what the informants said, as portrayed by Informant 3: "I can only tell you that there is no means". She/he further added: "Whatever you want to implement, programs or something, the school administration respond to you that, we have no budget, or just answers you by saying, spend out of your own pocket". In line with these findings, is a study by Peckover et al. (2013) found that there was a general concern related to the lack of resources for families, students, and school social workers. Similarly, Huxtable (1998) mentioned that school social workers reported feeling limited in their effectiveness. Reasons cited in his study for the failure of education welfare to develop into a true social work service include inadequate funding. 


\section{Workload and Occupational Stress}

Informants also emphasized the importance of workload and occupational stress that have been formed as theme and sub-themes in this study. According to the informants, workload is a challenge while performing their job. For instance, one informant remarked:

"The number of students is large. For example, I am expected to attend to 500 students in the school where I'm currently working, and I am the only one with a school social worker job title in the entire school. How can I play my role to the fullest? under such circumstances, such a large number of students, add to it the administrative works, and on top of all that, assigning the social worker to take on classes to cover for the absentee teachers... great stress and workload" -Informant 14.

In line with this finding, Cherniss et al. (1976) demonstrated that when a social worker has a case load of 200, he/she finds few adequate for maintaining them, all he/she can do is develop standardized routines for "processing" them. Leyba (2009), added that many school social workers work efficiently, for long hours, and with professional integrity and artistry.

However, according to Leyba (2009) study, a number of these social workers have so many tasks that it is challenging for them to fulfil mandates, pursue new initiatives, or complete certain activities at a professional level. Leyba (2009) maintained that, they may feel frustrated or burned out, and in some school districts, this problem is compounded when administrators overlook what school social workers have accomplished and focus only on what they have not been able to do. over time, burnout can affect social workers' emotional well-being and decrease their productivity (Leyba, 2009). Furthermore, Tam and Mong (2001) also emphasized this link between workload and stress, it was mentioned in their study that social workers suffer from increased stress, as the system is getting more and more outputoriented through the retention of fewer social worker in order to maintain the required output standard at an affordable cost. This is expected to be particularly true for school social workers who work in a secondary setting where they have to face additional stressors arising from those settings. However, their finding run contrary to the findings of this study in the sense that, the informants of their study were not experiencing a high level of job stress when compare with informants of this study.

\section{Sociodemographic Differences}

Another theme thought necessary by informants was the sociodemographic differences emerged through two the sub-themes; diversity nature of the city

\section{Cultural Diversity of the Society}

The informants emphasized facts about the cultural diversity of the society in Riyadh, the capital of the Kingdom of Saudi Arabia and the location of this study, which is reflected in schools. For example, one informant stated:

"Especially when you are in an environment where there are many family problems and poverty. Of course, also there is the level of education of the parents, when the mother is educated, with at least a high school or bachelors, such families are responsive to us as social workers and have some understanding of the role of the social workers. Such a family and mother would appreciate our work and knows that what we do is in the interest for her own daughter and that I am not against the student" -Informant 11. 


\section{Education Level}

One of the informants stated as below:

"I am facing difficulty when the family has a low level of education and it is tough where the tribalism is very high. This makes it difficult to communicate or reach an understanding with such families. Therefore, social workers must be aware of the cultural differences among the society in order to have less problems". - Informant 4

Based on the above responses of the informants, it was discovered in the study of Broussard (2003) maintaining that teachers need to understand the importance of and be prepared to involve all types of families in the education process. To do this, teachers must learn about diverse family styles and cultural backgrounds and realize that all families have strengths. Teacher education programs have not adequately addressed these issues. School social workers, who have should be providing individual and group services to students in the school setting, and should be well-versed in the knowledge and skills needed to work toward greater equity in home-school relations. The gap in teacher education provides an opportunity for school social workers to apply their theoretical knowledge of ecological and family systems and to share their knowledge about racial and ethnic diversity, family diversity, and family strengths (Broussard, 2003).

From the foregoing therefore, school social work has not seen such satisfactory progress in all countries \{Formatting Citation\}. Although, the study agrees with other researchers and practitioners that school social workers should do their best to increase their visibility and define their roles. This study recommends that national organizations must also work together to support school social workers' individual efforts. More articles in the professional literature that evaluate the systemic change efforts of school social workers would further enhance such efforts. Identification of professional preparation and competencies and implementation of consistent certification requirements across the country can help legitimize the school social work profession and ensure that the country have fully competent school social workers who are using best practices with students, families, and communities across the nation.

\section{Summary and Conclusion}

Many studies have been conducted on social work in Saudi Arabia, however, research on social work at school is under scrutiny that makes uncertainties and doubts among authorities and the research community. Social workers in Saudi schools carry out professional work of a distinct nature, they work with students and their parents, and they link the home to the school.. The social workers in Saudi schools perform work on an individual and group level, by facing problems that impede the practical achievement of the students. As such, the social workers face many difficulties and challenges that hinder them from performing their roles to the fullest. These challenges are at the level of legislation and laws that regulate work, and they are not always on their side. They also face various issues within the school environment by not understanding the nature of their roles by the school administration and its employees. In addition, the difficulties also involved in communicating with some parents cannot be overlooked either. This study tries to shed light on all these challenges, to draw a clear picture of all concerned, from the decision makers to the social workers themselves. The findings of the study provide insights to the governing body of the importance of the roles of social workers, and details of the difficulties and challenges. It was also discovered that because of 
the day-to-day challenges at some stage make the social workers seemingly forget or take incomplete responsibility for his role, one of the most difficult work so far is that of a social work at job. Not only are these challenges natural, but others are also artificially made to frustrate the efforts of social workers by some ministry officials or school leadership. Therefore, the findings of the study strongly suggest to establish an organization of their own and form the enactment of regulations that preserved the rights of social workers and enhanced their status and important roles. This study also recommended that the level of the efficiency of the work provided by unanimous specialists, as well as assisting decision-makers in a deeper understanding of the overall challenges that stand in their way to carry out their massive responsibilities.

The significance of this study arises from the belief that it deals with one of the most critical educational challenges in the KSA, particularly referring to the challengers of social workers at school as the study seeks the opinions of those who are directly involved. Based on that, this research paper is a vital addition for researchers interested in the social work fields. In addition, the findings of this research paper will enhance the existing body of knowledge on social work especially at school in Saudi Arabia through its scientific contribution to the improvement of more broad, improved and organized social work programs for the KSA schools.

In addition, this research adopted the system theory to explain the challenges face by school social workers in their workplace as a system. The principal theoretical implication of this study is that, it has contributed to the theory especially in the area of challenges affecting profession and how this challenges can be mitigated in the work environment as a system. The research paper contributed towards the development of more comprehensive, better organized social work programs for the KSA school. It further contributes to the body of knowledge, profound usefulness to government of the KSA, benefits to social institutions and agencies as well as educational institutions. It was however noted that the research paper was the first of its kind in the context of KSA schools, particularly using theory applied herein and with qualitative approach. This research paper also serves as an addition to other qualitative studies that examine, in depth information about social work, and it contributes essential information for researchers interested in the area.

\section{References}

Abu Al-Naser, M. M. (2017). Social work in the school field (Ed). Cairo: Arab Group for Training and Publishing.

Ahmadi, N. (2003). Globalisation of consciousness and new challenges for international social work. International Journal of Social Welfare, 12, 14-23.

Al-Ajlan, A. A. (2000). The social work role in the secondary schools in Saudi Arabia. Doctoral dissertation, The University of Hull. Digital Repository.

Alavi, K., Amin, A. S., Subhi, N., \& Sarnon, N. (2012). Social work at school: Understanding and dealing with child abuse. e-Bangi, 9 (1), 17 -37.

Albrithen, A., \& Briskman, L. (2014). Social work ethics in Saudi Arabia: An exploration. British Journal of Social Work, 45(7), 1-18.

Almaizar, H., \& A. Abdelhamed, K. (2018). Research trends in social work in Kingdom of Saudi Arabia. Journal of Sociology and Social Work, 6(2), 18-26. https://doi.org/10.15640/jssw.v6n2a4. 
Altshuler, S. J., \& Webb, J. R. (2009). School social work: Increasing the legitimacy of the profession. Children \& Schools, 31(4), 207-218. Retrieved from http://www.naswpress.org/publications/journals/cs.html.

Amin, S. M., Mohamad, M. S., \& Ahmad, T. L. T. (2019). The development of social work undergraduate programs in Malaysia public universities: Issues, challenges and opportunities. Pertanika Journal of Social Sciences and Humanities, 27(SI), 45 -59.

Balobaid, A., Qari, A., \& Al-zaidan, H. (2016). Genetic counselors' scope of practice and challenges in genetic counseling services in Saudi Arabia. International Journal of Pediatrics and Adolescent Medicine, 3(1), 1-6. https://doi.org/10.1016/j.ijpam.2015.12.002.

Becker, K. D., Mathis, G., \& Mueller, C. W. (2012). Barriers to treatment in an ethnically diverse sample of families enrolled in a community-based domestic violence intervention. Journal of Aggression, Maltreatment \& Trauma, 21(8), 829-850. https://doi.org/10.1080/10926771.2012.708013.

Ben-natan, M. (2014). Screening by healthcare staff for domestic violence against women in Israel - ethical and legal aspects. Journal of Family Violence, 29, 809-813. https://doi.org/10.1007/s10896-014-9625-2.

Broussard, C. A. (2003). Facilitating home - school partnerships for multiethnic families : School social workers collaborating for success. Children \& Schools, 25(4), 211-217.

Calis, N., \& Calis, S. T. (2015). Significance of supportive services in education: School social work as a new horizon in Turkey. Procedia - Social and Behavioral Sciences, 174, 10431047 https://doi.org/10.1016/j.sbspro.2015.01.792.

Cherniss, C., Egnatios, E. S., \& Wacker, S. (1976). Job stress and career development in new public professionals. Professional Psychology, 7(4), 428-436.

Christensen, J., Onul, D., \& Singh, P. (2018). Impact of ethnic civil conflict on migration of skilled labor. Eastern Economic Journal, 44(1), 18-29. https://doi.org/10.1057/s41302016-0069-7.

Crewell, J. W. (1998). Qualitative inquiry and research design: Choosing among five traditions. Thousand Oaks, CA, US: Sage Publication.

Darwish, S., Abdo, H., \& AlShuwaiee, W. M. (2018). Opportunities, challenges and risks of transition into renewable energy: the case of the Arab Gulf Cooperation Council. International Energy Journal, 18(4).

Dahlgren, L., Emmelin, M., \& Winkvist, A. (2007). A qualitative methodology for international public health. Umeå: Epidemiology and Public Health Sciences, Department of Public Health and Clinical Medicine, Umeå University.

Huxtable, M. (1998). School social work : An international profession. Social Work in Education, 20(2), 95-107.

Kelly, M. S., Frey, A. J., Alvarez, M., Berzin, S. C., Shaffer, G., \& Brien, K. O. (2010). School social work practice and response to intervention. Children \& Schools, 32(4), 201-209.

Leyba, E. G. (2009). Tools to reduce overload in the school social worker role. Children \& Schools, 31(1), 219-228.

Lopez, V., \& Whitehead, D. (2013) Sampling data and data collection in qualitative research. In: Nursing \& Midwifery Research: Methods and appraisal for evidence-based practice. 4th ed. (Schneider, Z., Whitehead, D., LoBiondo-Wood, G. \& Haber, J.). pp. 123-140.

Paat, Y. (2013). Working with immigrant children and their families: An application of Bronfenbrenner's Ecological Systems Theory. Journal of Human Behavior in the Social Environment, 23, 954-966. https://doi.org/10.1080/10911359.2013.800007. 
Patton, M.Q. (2002). Qualitative research and evaluation methods (third). Thousand Oaks, CA, US: Sage Publications.

Peckover, C. A., Vasquez, M. L., Housen, S. L. Van, Saunders, J. A., \& Allen, L. (2013). Preparing school social work for the future: An update of school social workers' tasks in lowa. Children \& Schools, 35(1), 9-17. https://doi.org/10.1093/cs/cds015.

Rogers, K. H., Luton, R., Biggs, H., Biggs, R. O., Blignaut, S., Choles, A. G., \& Carolyn, G. (2013). Fostering complexity thinking in action research for change in Social- Ecological Systems. Ecology and Society, 18(2), 31.

Rosenkoetter, S. E., Hains, A. H., \& Dogaru, C. (2007). Successful transitions for young children with disabilities and their families: Roles of school social workers. Children \& Schools, 29(1), 25-34.

Saleh, M. A. (1987). Counseling and guidance in the Kingdom of Saudi Arabia. International Journal for the Advancement of Counselling, 10, 277-286.

Sloan, L. M., Bromfield, N. F., Matthews, J., Rotabi, K. S., Sloan, L. M., Bromfield, N. F., Matthews, J., \& Smith, K. (2017). Social work education in the Arabian Gulf : Challenges and opportunities. Journal of Religion \& Spirituality in Social Work: Social Thought, 36(1-2), 199-214 https://doi.org/10.1080/15426432.2017.1311247.

Soliman, H. H. (2013). Social work in the Middle East.(1 $1^{\text {st }}$ ed.). Routledge. https://doiorg.sdl.idm.oclc.org/10.1080/03068375108731387.

Tam, T. S. K., \& Mong, L. P. K. (2001). Job stress, perceived inequity and burnout among school social workers in Hong Kong. International Social Work, 48(4), 467-483. https://doi.org/10.1177/0020872805053470. 